\title{
Consumer Satisfaction With Packaging Materials: Kano Model Analysis Approach
}

\author{
Maja BROZOVIĆ* , Dorotea KOVAČEVIĆ ${ }^{*}$, Josip BOTA
}

\begin{abstract}
Packaging can play a significant role in a purchasing decision. Packaging material is one of the most important components of packaging design. It can create an initial impression that may generate an opinion regarding the product's attributes. Despite a significant research focus on packaging, there is a lack of findings related to the consumers' perception of packaging materials. This paper investigates the influence of packaging materials on consumers' perception of product quality according to the Kano model of attributes classification. We used products from the current market which consumers use in daily life and can be commonly found on store shelves. The paper examined 14 quality attributes of different packaging materials using five-level Kano questionnaires. The results indicated that the attributes of particular packaging materials have an effect on the consumers' product choice. In addition, the results demonstrate that the attributes classified as attractive or one-dimensional have a strong impact on the consumers' satisfaction.
\end{abstract}

Keywords: consumer; Kano model; material; packaging; product

\section{INTRODUCTION}

Marketing strategy encourages product purchasing by positioning the brand in the minds of potential buyers through packaging. In this regard, packaging is a mediator between the customers and the products, with the intent to attract the consumers' attention and influence their purchase decision. The fact that about $70 \%$ of all decisions about purchasing packaged goods in a supermarket are made at the point of sale confirms the importance of packaging and its role in consumer buying decisions [1]. The relationship between the consumers' purchasing choices and packaging is a key issue that manufacturers of packaged products must understand in order to develop effective packaging designs. Well-designed packaging affects the attractiveness at the point of purchase, and thus plays a critical role in achieving brand choice [2-4].

\subsection{Packaging Design and Consumers' Perception}

The added value has a major influence on the customers' expectations [5]. The added value can be created by professional packaging design based on a systematic approach to the selection of visual elements. Visual elements (such as graphics, typography, size, shape, colour) play an important role in purchase decisions, while informational elements (product information, material and technology used) are related to the cognitive intention in the pre-purchase stage [6]. Many studies demonstrated the effects of packaging design on the consumers' perception and purchase decisions. A study conducted by Silayoi and Speece [7] showed that consumers rely on their perception of several packaging elements (such as graphics, colour, shape, size and product information) when purchasing a product. Another study, which investigated the perception of minimally processed food products, also showed that some packaging elements, such as colour or product visibility, influenced consumers' product choices. Rebollar et al. [8] demonstrated the powerful role of packaging, suggesting that some design features (colour and shape) can influence the consumers' willingness to buy a product. The influence of packaging was also found in a study of consumers' preferences in choosing dairy products [9]. Furthermore, some previous studies showed that, in situations where consumers cannot rely on taste, odour or texture of a food product, they rely on extrinsic characteristics such as packaging and its attributes [10]. This is important, because when the consumers are faced with a new packaging on a market shelf, they are consequentially forced to make a quality assessment through the packaging design without having any experience with the product [11].

\subsection{Packaging Materials and Consumers' Perception}

Sometimes, packaging material can influence the quality of a product and affect the consumers' perception of the brand [12]. Packaging technology (which transmits a message of easy use) plays one of the most important roles on the likelihood of buying a product [13]. As an informational element, it has to balance product protection with other aspects such as materials, environmental regulations, waste disposal, etc. Innovative or user-friendly packaging attracts consumers' attention and can boost sales in a competitive environment [14]. One of the keys for successful packaging is the selection of materials that best meet the demands of product characteristics, marketing aspects, environmental issues and management, as well as total costs. Optical and colorimetric properties should also be taken into consideration [15]. The selection of packaging materials depends on the mechanical properties, cost effectiveness, ecological aspects and design as well as the type of product that is being packaged. The most commonly used materials in food packaging are glass, plastic, cardboard, paper laminates and metals. Glass is resistant to gases and vapours and can maintain product freshness without influencing its taste or flavour. Glass is more environmentally friendly because it is reusable and recyclable. The disadvantages are its susceptibility to breakage due to impact or thermal shock. Metal as a packaging material is appreciated because of its combination of mechanical and barrier properties, recyclability and acceptance by consumers [14], while paper and cardboard are used mainly for one-use products. Recently, the use of recycled paper and cardboard has increased. Contact time and temperature have a significant impact on the migration of contaminants in foods as well as high-fat foods [16]. As a response to this migration 
problem, polymers have been used for food packaging in recent decades due to the significant increase in mechanical and barrier properties that they provide to environmentally friendly food packaging materials $[17,18]$. Researches are increasingly focused on the development of biodegradable food packaging made from bio polymeric materials in order to reduce the constantly growing plastic waste [19].

Micro and nano-structured metal-based materials can be built into contact polymers to enhance the mechanical and barrier properties, prevent plastic photo degradation and extend the shelf-life of food [20]. The importance of the packaging material is recognized by the consumers. They tend to use practical packaging with minimal impact on the environment. A majority of consumers are more prone to recyclable materials such as glass and paper, especially in the case of eco-friendly packaging [21, 22].

Consumers' tendencies toward certain packaging materials depend on a number of factors such as age, financial power, lifestyle, information about material properties, and legislations. Previous research indicated that older people prefer glass when it comes to packaging materials. Transparency was recognized as an advantageous characteristic since glass enables the visual inspection of the content [23-25]. Furthermore, older consumers are less concerned about packaging materials, while younger people showed greater interest and knowledge about quality criteria and material safety [26].

\subsection{Kano's Theory of Attractive Quality}

The Kano model of attractive quality [27] has been used in the product development process to investigate the impact of various product quality attributes on consumer satisfaction. Löfgren and Nilsson [28] have classified the qualitative attributes of daily product packaging according to Kano's theory of attractive quality. The starting point was the division of the products' packaging characteristics, in accordance with the semantic product theory, into three entities: the technical, the ergonomic and the communicative entity [29]. The technical entity includes all elements and functions related to the construction and production of a product. The ergonomic entity refers to the usability aspect of the product. The communicative entity refers to the product's ability to effectively transmit a message to users.

The study of Löfgren and Nilsson [28] has shown that quality attributes in technical terms can be considered creators of attractive quality. The technical entity is required for creating an advantage that makes the product unique on the market. The ergonomic entity enables the customers to compare different brands which is important when using a product. Packaging should be both functional and attractive [30]. If the product packaging is difficult to use or non-functional, the buyer will probably consider purchasing a different brand next time. The communicative entity contributes little to the creation of customer satisfaction. Contrary, these attributes are important for eliminating dissatisfaction. The results showed that there are quality packaging attributes, such as recyclability and reusability that are appealing to customers during purchasing and product decision making.

The purpose of the Kano model is practical. A product with the potential of offering a high degree of satisfaction may not always result in a high level of customer satisfaction. The Kano model can help identify the substantial product features that lead to a satisfied customer. Furthermore, this method tends to shine a light on the product characteristics that can cause problems for the customers and their subsequent dissatisfaction with the product. Detecting these disadvantages can lead towards resolving and improving product features, and can enhance customer satisfaction.

\subsection{The Purpose of the Study}

Since consumers perceive different packaging functions differently, it is necessary to consider certain quality attributes and their impact on consumer satisfaction. One of our research questions was how some attributes of the packaging material contribute to greater consumer satisfaction. Other issues that this paper deals with are focused on the convenience of product materials and their impact on the consumers' perception of environmental issues. The influence of different packaging materials on the consumer's perception of the quality of the products is the main subject of this paper.

Our investigation is based on Kano's theory of attractive quality, and it explores how 14 (five technical and nine ergonomic) qualitative attributes of packaging are perceived by consumers. The choice of packaging material was used as a dependent variable while the quality attributes were used as independent variables.

The purpose of this study was to determine the degree of consumer satisfaction with the products packed in different packaging materials with regard to the technical and ergonomic attributes of quality according to the Kano model of attractive quality. Additionally, we touched upon the participants' ecological awareness in the context of packaging materials.

\section{MATERIALS AND METHODS}

Data collection was conducted through structured interviews with 80 participants (45 female, 35 male; age range $25-45$ years, mean age 30.5 years). The participants are frequent users of the nutritional products presented in the experiment. The survey was conducted in a room at the University of Zagreb Faculty of Graphic Arts. All the interviewees participated in the study voluntarily. Three food products were chosen for the study. The selection was based on the availability of the products in the current market and the types of products that the consumers use in daily life and can commonly be found on store shelves. The investigation included the following type of packaging materials: glass, rigid plastic (high-density polyethylene HDPE), tin, and flexible composite material. Flexible materials in our study were composed of multiple layers: instant coffee packaging was composed of LDPE (low density polyethylene) and Al (aluminium); cocoa powder packaging was composed of LDPE and PET (poly(ethylene terephthalate) and ground cinnamon packaging was composed of PET, PAP (paper), Al and PE (polyethylene).

At the beginning of the interview, the product samples were placed in front of the participants. The samples 
consisted of three food brands packaged in different materials:

-Instant coffee (200 g) packed in glass, tin, and flexible composite material (Fig. 1).

-Cocoa powder (400 g) packed in rigid plastic and flexible composite material (Fig. 2).

-Ground cinnamon (54 g) packed in glass and flexible composite material (Fig. 3).

For publication purposes, the brand logo was omitted in Fig. 1 to Fig. 3. During the experiment, the participants viewed the packaging with all visual information, including the logo.

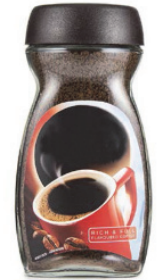

a)

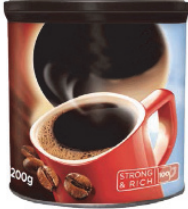

b)

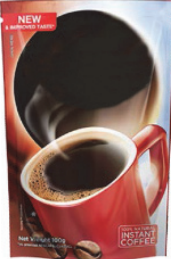

c)
Figure 1 Test samples for coffee: a) glass, b) tin, c) flexible composite material

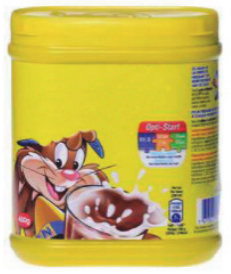

a)

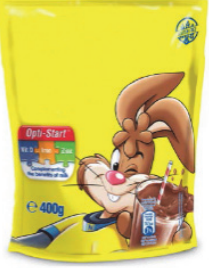

b)
Figure 2 Test samples for cocoa: a) rigid plastic, b) flexible composite material

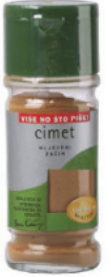

a)

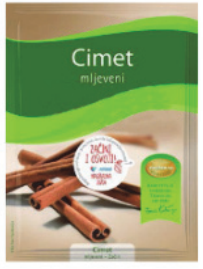

b)
Figure 3 Test samples for cinnamon: a) glass, b) flexible composite material

All samples were dry food products. The mass of the product was identical within the same product type. In order to reduce the cost effect, the product price was omitted as an influential and measurable factor. Participants had to choose the packaging they would most likely buy in the store and briefly explain their choice of packaging material. Each participant had to choose one packaging among the offered versions for every product group. Specifically, a participant had to select the most preferred coffee packaging among three packaging samples that differed by material, the most preferred cocoa among two packaging and the most preferred ground cinnamon among two offered packaging. The choice-tasks were not time limited. Subsequently, we wanted to investigate the participants' satisfaction with their choice of packaging material based on its characteristics more deeply.
The Kano model questionnaire was constructed and carried out using a survey. More precisely, a five-level Kano questionnaire was used to determine the way in which each products' material attributes affected customer satisfaction or dissatisfaction. Five possible alternative responses were given as answer choices for the satisfaction or dissatisfaction [31] as shown in Tab. 1. The investigation included five technical and nine ergonomic quality attributes (shown in Tab. 2 to Tab. 4).

Table $1 \mathrm{~A}$ pair of customer requirements questions in a Kano five-level questionnaire

\begin{tabular}{|c|c|}
\hline Functional form of the question & Dysfunctional form of the question \\
\hline $\begin{array}{l}\text { If a package is easy to open, } \\
\text { how do you feel? }\end{array}$ & $\begin{array}{l}\text { If a package is easy to open, } \\
\text { how do you feel? }\end{array}$ \\
\hline 1. I like it that way. & 1. I like it that way. \\
\hline 2. It must be that way & 2. It must be that way \\
\hline 3. I am neutral & 3. I am neutral \\
\hline 4. I can live with it that way & 4. I can live with it that way \\
\hline 5. I dislike it that way. & 5. I dislike it that way. \\
\hline
\end{tabular}

The participants were asked to rate how they perceived the importance of each attribute.

\section{DISCUSSION OF RESULTS}

The Kano model categories of quality attributes for each product were classified according to the Customer Satisfaction Index (CSI) as attractive, one-dimensional, must-be, indifferent or reverse [31]. Must-be quality attributes create dissatisfaction with absence, but do not create satisfaction with their presence. One-dimensional quality attributes result in an increase of customer satisfaction that proportionally grows with the fulfilment of those attributes. Indifferent attributes refer to characteristics that are neither good nor bad, and they do not lead to people's satisfaction or dissatisfaction. Attractive attributes can lead to satisfaction if they are fully fulfilled, but they do not bring dissatisfaction if they are not achieved. CSI was calculated using the average number of customers who consider being satisfied with the attributes' presence or sufficiency and the average number of customers who consider being dissatisfied with the attributes' absence or presence.

Categories were selected for each attribute and the calculation of the average satisfaction/dissatisfaction was based on the percentage of the participants' responses. Calculating the average attribute was derived according to Berger et al. [31]. The results demonstrated that people's satisfaction can be raised by achieving a particular attribute. Tab. 2 to Tab. 4 present the satisfaction evaluation results based on the participants' answers in the Kano questionnaires dependent on the attributes' presence.

Tab. 2 shows the classification of certain quality attributes for instant coffee and the average for satisfaction/dissatisfaction. Half of the respondents $(50 \%)$ selected tin, while a similar number $(43.7 \%)$ selected glass packaging.

Tab. 3 shows the classification of certain quality attributes for the cocoa powder and the average results of satisfaction/dissatisfaction. The majority of the participants chose the plastic packaging $(67.5 \%)$, while a 
notably smaller number of respondents (32.5\%) selected the flexible composite material.

Tab. 4 shows the classification of certain quality attributes for ground cinnamon and the average satisfaction/dissatisfaction. Most of the participants $(67.5 \%)$ selected the glass packaging, while the flexible composite material was chosen by considerably fewer respondents $(32.5 \%)$.

Table 2 Quality attributes classification for instant coffee

\begin{tabular}{|c|c|c|c|c|c|c|}
\hline \multirow{2}{*}{$\begin{array}{l}\text { QUALITY ATTRIBUTES } \\
\text { TECHNICAL ENTITY: }\end{array}$} & \multicolumn{4}{|c|}{ Classification } & \multirow{2}{*}{$\frac{\text { Satisfaction }}{\mathbf{A}+\mathbf{O} / \mathbf{A}+\mathbf{O}+\mathbf{M}+\mathbf{I}}$} & \multirow{2}{*}{$\begin{array}{c}\text { Dissatisfaction } \\
\mathrm{O}+\mathrm{M} /(\mathbf{A}+\mathbf{O}+\mathrm{M}+\mathrm{I}) \\
*(-1)\end{array}$} \\
\hline & $\begin{array}{l}\mathbf{M} \\
\%\end{array}$ & $\begin{array}{l}\mathbf{I} \\
\%\end{array}$ & $\begin{array}{l}\mathbf{O} \\
\%\end{array}$ & $\begin{array}{l}\mathbf{A} \\
\%\end{array}$ & & \\
\hline Protection & 30 & 11 & 53 & 6 & 0.59 & -0.82 \\
\hline Leaking the aroma & 36 & 23 & 23 & 18 & 0.41 & -0.58 \\
\hline Resealability & 6 & 30 & 17 & 47 & 0.65 & -0.23 \\
\hline Recyclable material & 12 & 23 & 42 & 23 & 0.65 & -0.53 \\
\hline Attractiveness of the label & - & 47 & 11 & 42 & 0.53 & -0.12 \\
\hline \multicolumn{7}{|l|}{ ERGONOMIC ENTITY: } \\
\hline Easy to grip & 5 & 23 & 30 & 42 & 0.70 & -0.35 \\
\hline Easy to open & 5 & 23 & 30 & 42 & 0.70 & -0.35 \\
\hline $\begin{array}{l}\text { Facilitates the sorting out of } \\
\text { household waste }\end{array}$ & 23 & 36 & 23 & 18 & 0.41 & -0.47 \\
\hline Reusable when empty & - & 29 & 18 & 53 & 0.70 & -0.18 \\
\hline Easy to dose & - & 18 & 23 & 59 & 0.82 & -0.23 \\
\hline Fits in storage spaces & 5 & 18 & 30 & 47 & 0.76 & -0.35 \\
\hline Contains just the right quantity & 53 & 17 & 30 & - & 0.29 & -0.82 \\
\hline $\begin{array}{l}\text { Easy to throw in the } \\
\text { household waste }\end{array}$ & - & 23 & 47 & 30 & 0.76 & -0.47 \\
\hline User-friendly & - & 28 & 30 & 42 & 0.70 & -0.29 \\
\hline
\end{tabular}

M - must-be; I - indifferent; $\mathbf{O}$ - one-dimensional; $\mathbf{A}$ - attractive

Table 3 Quality attributes classification for cocoa powder

\begin{tabular}{|c|c|c|c|c|c|c|}
\hline \multirow{2}{*}{$\begin{array}{l}\text { QUALITY ATTRIBUTES } \\
\text { TECHNICAL ENTITY: }\end{array}$} & \multicolumn{4}{|c|}{ Classification } & \multirow{2}{*}{$\begin{array}{c}\text { Satisfaction } \\
\mathbf{A}+\mathbf{O} / \mathbf{A}+\mathbf{O}+\mathbf{M}+\mathbf{I}\end{array}$} & \multirow{2}{*}{$\begin{array}{c}\text { Dissatisfaction } \\
\mathbf{O}+\mathbf{M} /(\mathbf{A}+\mathbf{O}+\mathbf{M}+\mathbf{I}) \\
*(-1)\end{array}$} \\
\hline & $\begin{array}{l}\mathbf{M} \\
\%\end{array}$ & $\begin{array}{l}\mathbf{I} \\
\%\end{array}$ & $\begin{array}{l}\mathbf{O} \\
\%\end{array}$ & $\begin{array}{l}\mathbf{A} \\
\%\end{array}$ & & \\
\hline Protection & 39 & 21 & 34 & 6 & 0.39 & -0.72 \\
\hline Leaking the aroma & 34 & 27 & 28 & 11 & 0.39 & -0.61 \\
\hline Resealability & 21 & 17 & 45 & 17 & 0.61 & -0.66 \\
\hline Recyclable material & 11 & 27 & 28 & 34 & 0.61 & -0.39 \\
\hline Attractiveness of the label & - & 50 & 11 & 39 & 0.50 & -0.11 \\
\hline \multicolumn{7}{|l|}{ ERGONOMIC ENTITY: } \\
\hline Easy to grip & 28 & 27 & 39 & 6 & 0.45 & -0.66 \\
\hline Easy to open & 22 & 23 & 39 & 16 & 0.56 & $\begin{array}{ll}-0.61 \\
\end{array}$ \\
\hline $\begin{array}{l}\text { Facilitates the sorting out of } \\
\text { household waste }\end{array}$ & 16 & 45 & 16 & 23 & 0.39 & -0.33 \\
\hline Reusable when empty & 12 & 33 & 16 & 39 & 0.56 & -0.28 \\
\hline Easy to dose & 27 & 11 & 39 & 23 & 0.61 & -0.66 \\
\hline Fits in storage spaces & 6 & 21 & 34 & 39 & 0.72 & -0.39 \\
\hline Contains just the right quantity & 23 & 22 & 39 & 16 & 0.56 & -0.61 \\
\hline $\begin{array}{l}\text { Easy to throw in the } \\
\text { household waste }\end{array}$ & 17 & 21 & 34 & 28 & 0.61 & -0.50 \\
\hline User-friendly & 6 & 27 & 39 & 28 & 0.67 & -0.45 \\
\hline
\end{tabular}

M - must-be; I - indifferent; $\mathbf{O}$ - one-dimensional; $\mathbf{A}$ - attractive

Table 4 Quality attributes classification for ground cinnamon

\begin{tabular}{|c|c|c|c|c|c|c|}
\hline \multirow{2}{*}{$\begin{array}{l}\text { QUALITY ATTRIBUTES } \\
\text { TECHNICAL ENTITY: }\end{array}$} & \multicolumn{4}{|c|}{ Classification } & \multirow{2}{*}{$\frac{\text { Satisfaction }}{\mathbf{A}+\mathbf{O} / \mathbf{A}+\mathbf{O}+\mathbf{M}+\mathbf{I}}$} & \multirow{2}{*}{$\begin{array}{c}\text { Dissatisfaction } \\
\begin{array}{c}\mathrm{O}+\mathbf{M} /(\mathbf{A}+\mathbf{O}+\mathbf{M}+\mathbf{I}) \\
{ }^{*}(-1)\end{array} \\
\end{array}$} \\
\hline & $\begin{array}{l}\mathbf{M} \\
\%\end{array}$ & $\begin{array}{l}\mathbf{I} \\
\%\end{array}$ & $\begin{array}{l}\mathbf{o} \\
\%\end{array}$ & $\begin{array}{l}\mathbf{A} \\
\%\end{array}$ & & \\
\hline Protection & 28 & 23 & 39 & 10 & 0.50 & -0.67 \\
\hline Leaking the aroma & 23 & 15 & 39 & 23 & 0.61 & -0.61 \\
\hline Resealability & 5 & 22 & 23 & 50 & 0.72 & -0.27 \\
\hline Recyclable material & 5 & 33 & 23 & 39 & 0.61 & -0.27 \\
\hline Attractiveness of the label & 6 & 67 & 11 & 16 & 0.28 & -0.16 \\
\hline \multicolumn{7}{|l|}{ ERGONOMIC ENTITY: } \\
\hline Easy to grip & - & 45 & 33 & 12 & 0.56 & -0.33 \\
\hline Easy to open & 34 & 27 & 16 & 13 & 0.39 & -0.50 \\
\hline $\begin{array}{l}\text { Facilitates the sorting out of } \\
\text { household waste }\end{array}$ & 11 & 45 & 16 & 28 & 0.45 & -0.27 \\
\hline Reusable when empty & - & 33 & 12 & 45 & 0.66 & -0.22 \\
\hline Easy to dose & 5 & 22 & 45 & 28 & 0.72 & -0.50 \\
\hline Fits in storage spaces & - & 27 & 28 & 45 & 0.72 & -0.27 \\
\hline Contains just the right quantity & 28 & 21 & 34 & 17 & 0.50 & -0.61 \\
\hline $\begin{array}{l}\text { Easy to throw in the } \\
\text { household waste }\end{array}$ & 6 & 27 & 39 & 28 & 0.66 & -0.44 \\
\hline User-friendly & 12 & 27 & 39 & 22 & 0.61 & -0.50 \\
\hline
\end{tabular}

M - must-be; I - indifferent; $\mathbf{O}$ - one-dimensional; $\mathbf{A}$ - attractive

The obtained quality attributes classification results of packaging materials investigated in this study are presented in Tab. 5.
Table 5 An overview of classification quality attributes of packaging materials

\begin{tabular}{|l|l|}
\hline QUALITY ATTRIBUTES & Classification summary for all the materials \\
\hline Technical entity: & \\
\hline 1 - Protection & combination (one-dimensional and must-be) \\
\hline 2- Leaking the aroma & combination (must-be and one-dimensional) \\
\hline 3 - Resealability & combination (attractive and one-dimensional) \\
\hline 4 - Recyclable material & combination (attractive and one-dimensional) \\
\hline 5- Attractiveness of the label & indifferent \\
\hline Ergonomic entity: & \multicolumn{2}{|l|}{} \\
\hline 6- Easy to grip & combination (one-dimensional, attractive and indifferent) \\
\hline 7 - Easy to open & combination (must-be, one-dimensional and attractive) \\
\hline $\begin{array}{c}\text { 8- Facilitates the sorting out } \\
\text { of household waste }\end{array}$ & indifferent \\
\hline 9- Reusable when empty & attractive \\
\hline 10 - Easy to dose & combination (one-dimensional and attractive) \\
\hline 11 - Fits in storage spaces & attractive \\
\hline 12 - Contains just the right quantity & combination (one-dimensional and must-be) \\
\hline $\begin{array}{c}13-\text { Easy to throw in the } \\
\text { household waste }\end{array}$ & one-dimensional \\
\hline 14 - User-friendly & combination (one-dimensional and attractive) \\
\hline
\end{tabular}

Pairs of better and worse points of satisfaction and dissatisfaction for each technical and ergonomic attribute of the packaging materials were plotted in better-worse diagrams. The negative values in front of the worse points were ignored in the graph for clarity. These figures show the individual attributes' influence on the consumers' perception of quality based on the packaging materials: tin (Fig. 4), plastic (Fig. 5) and glass (Fig. 6).

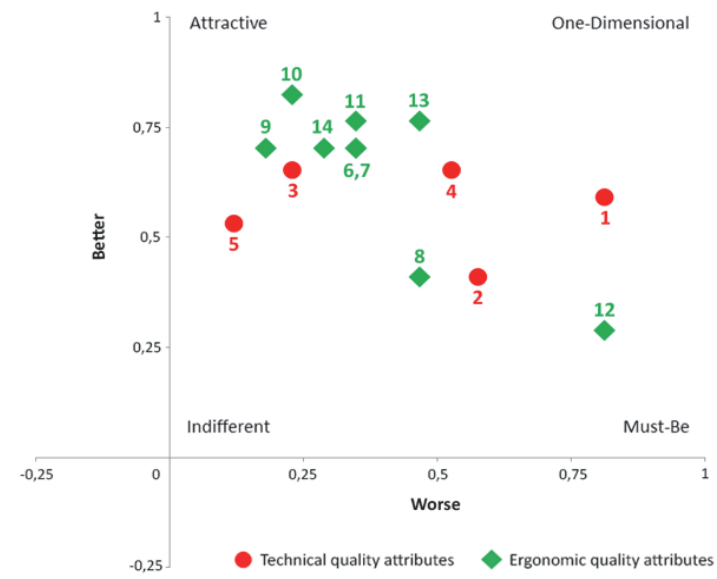

Figure 4 Technical and ergonomic quality attributes plotted in better-worse chart for tin as a packaging material

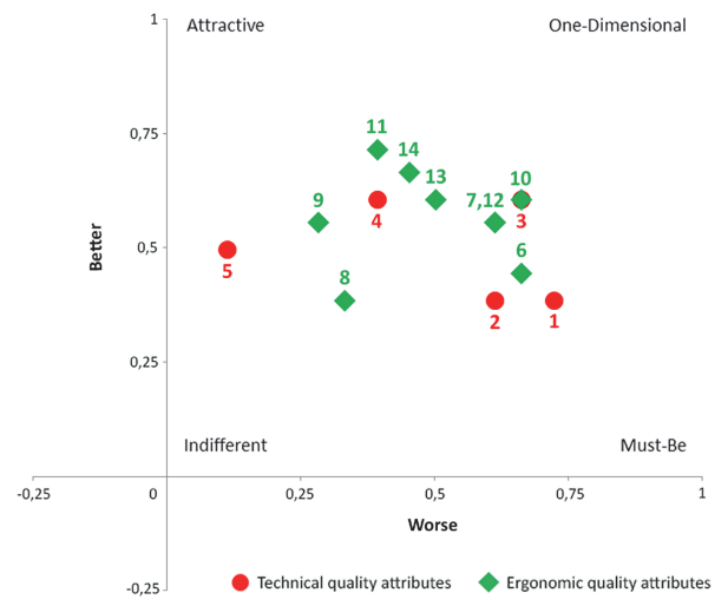

Figure $\mathbf{5}$ Technical and ergonomic quality attributes plotted in better-worse chart for plastic as a packaging material 


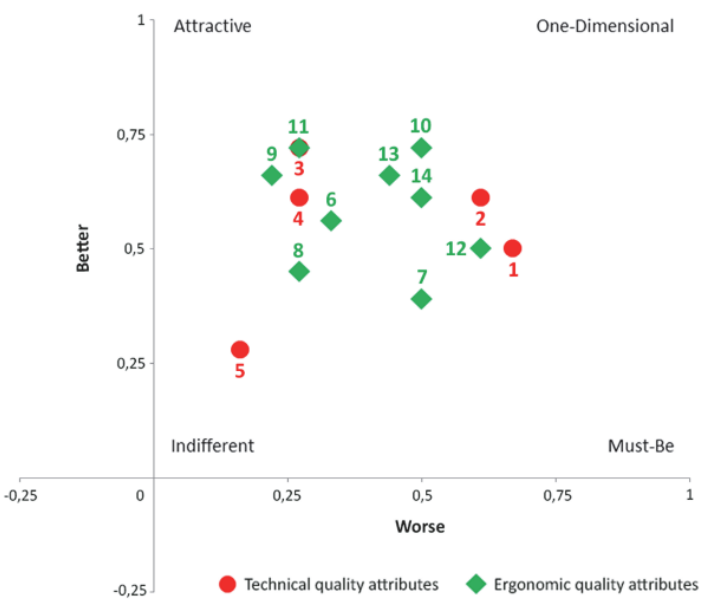

Figure 6 Technical and ergonomic quality attributes plotted in better-worse chart for glass as a packaging material

\subsection{Technical Entity}

Technical attributes are considered to be the creators of attractive quality, while ergonomic attributes are considered as one-dimensional quality [28]. The attribute "Attractiveness of the label" was expected to be estimated for all packaging materials as indifferent, since our research was based on different packaging materials rather than aesthetics and the communicative attributes which were omitted. "Recyclable material" was classified as attractive for plastic and glass, while one-dimensional for tin. The attractive attributes were not surprising, since the research by Magnier et al. [32] showed that packaging sustainability has a positive impact on the perceived quality of a product and adds additional value. "Resealability" was characterized as attractive for tin, and one-dimensional for plastic. These two attributes ("Recyclable material" and "Resealability") increased customer satisfaction when it came to glass. This is a surprising result since glass is a commonly used material for containers that can be resealed and most people have a habit of sorting glass during waste disposal.

"Leaking the aroma" was ranked as a must-be attribute for tin and plastic, while one-dimensional for glass. "Protection" was evaluated as a must-be attribute for plastic, and one-dimensional for tin and glass. "Protection" and "Leaking the aroma" had a reduced effect on the satisfaction regardless of the packaging material. With regard to the Better-Worse diagrams of different packaging materials, customer satisfaction can be enhanced by improving the attribute with the ability to "Recycle materials" and "Resealability", while "Protection" and "Leaking the aroma" do not create a sense of satisfaction.

\subsection{Ergonomic Entity}

Ergonomic attributes were considered as a onedimensional quality that is essential during use of the product. The highest degree of customer satisfaction was observed at "Reusable when empty" and "Fits in storage spaces". They were classified as attractive attributes regardless of the type of packaging material. A high degree of satisfaction has also been demonstrated with "Userfriendly" packaging. "Easy to throw in the household waste" was classified as a one-dimensional quality, which indicates that the users have ecological awareness. "Easy to dose" is an attribute that greatly affected the satisfaction especially with the tin packaging where it was classified as an attractive attribute. The only attribute assessed as indifferent was "Facilitates the sorting out of household waste" regardless of the packaging material. "Easy to grip" and "Easy to open" were the attributes which depended on the material because the categories ranged from the mustbe to the attractive. "Contains just the right quantity" was an attribute that was classified as a must-be for tin and onedimensional for plastic and glass. This was not surprising, especially in the case of glass. In many instances, glass is transparent and its opacity allows the consumers to see what is inside the container. This advantage of transparency was highlighted by some previous studies investigating the consumers' responses to packaging, such as perception of packaging instrumentality [33], buying intentions [34] and expectations [24, 35]. Simply put, people like to know what to expect from the perceived volume of the packaging. Therefore, visibility of packaged content and its quantity can definitely prevent consumer disappointment. To achieve a greater degree of user satisfaction, it is necessary to keep the must-be attributes, increase the one-dimensional and attractive, and avoid the indifferent and reverse attributes [36].

Given that a cup of coffee is commonly consumed on a daily basis, coffee is being considered as a food product which is more frequently used than cocoa and cinnamon. In the light of our results, when designing packaging for a frequently used food product, such as coffee, it is important to achieve easy and simple packaging usability from an ergonomic point of view. On the other hand, for products such as cocoa and cinnamon, our results suggest that the functionality of the packaging shapes and materials gives people greater satisfaction.

\subsection{Material Preferences for Coffee Packaging}

When choosing the preferred material for instant coffee, half of the participants selected tin, while a negligibly smaller number selected glass. This might be because when buying a product for the first time, consumers choose a tougher packaging (glass) to ensure that they have a permanent container for future use, which allows them to select a lighter material (tin) in later purchases. Related research was conducted by Klaiman et al. [37], whose findings have shown that $34 \%$ of customers emphasize the usability of packaging and packaging materials, while $31 \%$ of the customers reported the easily degradable properties of packaging materials which are not harmful for the environment as the greatest factor in their purchasing decision. The participants explained that they selected lighter materials to facilitate easier transport of the product from the place of purchase. Tin as one of the selected materials had the best-judged ergonomic attributes in comparison to other packaging materials (Fig. 4). It follows that this packaging material possesses characteristics that affect customer satisfaction more than glass and flexible composite material. The reason for this result could be found in the structural stability and light weight which enables easy handling of the packaging. 


\subsection{Material Preferences for Cocoa Powder Packaging}

In the case of selecting the material for cocoa powder packaging, participants had to choose between rigid plastic and flexible composite material. The plastic packaging was preferred for practical reasons of use and its protective function. The participants indicated that packaging for powdered content that cannot be re-closed provides a risk of harmful substances penetrating into the product. Therefore, they tend to prefer solid and stable packaging that protects the contents. Unlike the tin (the previously analysed coffee packaging material), the plastic was predominantly evaluated as one-dimensional from the standpoint of ergonomic attributes. Plastic packaging can be more environmental-friendly compared to other packaging materials in some cases [38]. In contrast, our findings indicated that plastic as a packaging material was evaluated as less environmentally friendly, unlike glass.

\subsection{Material Preferences for Cinnamon Packaging}

For ground cinnamon, many participants selected glass as a preferred packaging material because of its functionality that allows "Easy to dose" and "Easy to open". This result is consistent with the findings discovered by Arboretti and Bordignon [39] who investigated qualitative attributes, such as reusability and the existence of a lid on the packaging. These attributes increased customer satisfaction. A significant increment of satisfaction was also reported in a study by Kim and Lee [25] which showed that the packaging material transparency was perceived as an attractive attribute. It seems that the transparency properties of the glass containers used in our study influenced our participants in a similar way. The functionality of transparent packaging was also demonstrated in a study by Vilnai-Yavetz and Koren [33] where see-through packaging was found to indicate better instrumentality than non-transparent packaging.

In the particular case of preferring glass as a packaging material in our study, the environmental aspect should not be overlooked. When it comes to packaging materials with the highest recyclability, Klaiman et al. [37] argued that consumers probably believe that plastic is the most important material to recycle, more so than glass and carton. On the contrary, participants in our research claimed that by choosing glass over plastic packaging, they contribute to the ecological aspect.

\subsection{Technical and Ergonomic Quality Attributes}

When comparing our results with previous studies that investigated quality attributes [28, 40], the overall classification of the quality attributes was changed. Technical attributes, such as "Protection" and "Leaking the aroma", that were previously classified as must-be attributes, moved to the one-dimensional attributes in this study. This suggests that these quality attributes largely depend on material characteristics. "Resealability" was evaluated as a combination of attractive and onedimensional, so it is advisable for designers to pay attention to materials in packaging development. "Recyclable material" and "Attractiveness of the label" stayed unchanged regardless of different materials.

Generally, in the case of ergonomic attributes, there were more changes in classification. "Easy to grip" and "Easy to open" were influenced by packaging materials. These attributes resulted with completely different evaluations depending on the type of material. Interestingly, "Facilitates the sorting out of household waste" was moved from one-dimensional to indifferent, in opposition to previous studies by Löfgren et al. [40]. This stresses the need for more research attention on the materials' structure and its performance. "Reusable when empty" and "Fits in storage spaces" were positioned as an attractive quality attribute and that has changed greatly in comparison with the classification suggested by Löfgren et al. [40]. One explanation for this could be associated with modern lifestyle where people tend to use all resources rationally. "Easy to dose" and "User-friendly" are more attractive quality attributes. "Contains just the right quantity" moved from attractive to the combination of onedimensional and must-be, opposite to that suggested by Löfgren et al. [40]. This can be interpreted by the distrusting attitude of our participants toward the manufacturers. "Easy to throw in the household waste" was classified the same as in previous studies. Research related to new packaging design [1] confirms some findings from our study. Consumers evaluate packaging on the basis of their ergonomic attributes, "Ease of use" and "Ease of handling", and those positive associations correlate with their purchase intention and all other types of productrelated experience. This implies that usability is an important aspect in packaging design. Packaging should facilitate all users' actions directed to getting a product. Furthermore, it should assist the consumers in their everyday tasks which involve choosing and handling packaging more and more each day.

\section{CONCLUSION}

This study continues previous researches on attributes that provide optimal quality related to packaging materials. Based on the overall view of quality attributes investigated in this study, the influence of packaging materials on the quality attributes is considerable. Tin had the most successful quality attributes, followed by glass and plastic. In comparison to the categorisation suggested by previous studies, our research showed differences in the users' satisfaction in relation to the packaging material. The categorisation depends less on the packaging material in the case of technical attributes than it does in the case of ergonomic attributes.

In summary, this study presents that the degree of customer satisfaction is not largely influenced by the material, but by the attributes offered by each material. When selecting packaging materials, users' perception will be affected by the recyclability, functionality and convenience of use along with the necessary product protection. Attention-grabbing properties and attractiveness play a great role in brand choice. Our findings provide practical guidelines for the design of attractive packaging products, enabling designers to create a successful package. Understanding how consumers perceive products and their packaging is of strategic 
importance for marketers, managers and designers. The benefits of packaging material can provide useful information for all those who want to enhance packaging impact at point of sale.

As with all studies based on subjective responses, our study has limitations. One of them is the small sample group. Another limitation is that the research was conducted under laboratory conditions that differ from real-life situations in which participants purchase the products used in this study. We believe that future research will provide more valid assessments of packaging effects in accordance with a realistic supermarket environment.

\section{REFERENCES}

[1] Holmes, G. R. \& Paswan, A. (2012). Consumer reaction to new package design. Journal of Product \& Brand Management, 21(2), 109-116. https://doi.org/10.1108/10610421211215553

[2] Wang Edward, S. T. (2013). The influence of visual packaging design on perceived food product quality, value, and brand preference. International Journal of Retail \& Distribution Management, 41(10), 805-816. https://doi.org/10.1108/IJRDM-12-2012-0113

[3] Orth, U. R. \& Malkewitz, K. (2008). Holistic Package Design and Consumer Brand Impressions. Journal of Marketing, 72(3), 64-81. https://doi.org/10.1509/JMKG.72.3.064

[4] Kovačević, D., Brozović, M., \& Itrić, I. K. (2019). Eco-mark on product packaging and its effect on the perception of quality. Journal of Graphic Engineering and Design, 10(2), 17-24. http://doi.org/10.24867/JGED-2019-2-017

[5] Auttarapong, D. (2012). Package Design Expert System Based on Relation between Packaging and Perception of Customer. Procedia Engineering, 32, 307-314. https://doi.org/10.1016/j.proeng.2012.01.1272

[6] Estiri, M., Hasangholipour, T., Yazdani, H., Nejad, H. J., \& Rayej, H. (2010). Food Products Consumer Behaviors: The Role of Packaging Elements. Journal of Applied Sciences, 10(7), 535-543.

[7] Silayoi, P. \& Speece, M. (2004). Packaging and purchase decisions: a focus group study on the impact of involvement level and time pressure. British Food Journal, 106(8), 607628. https://doi.org/10.1108/00070700410553602

[8] Rebollar, R., Lidón, I., Serrano, A., Martin, J., \& Fernández, M. J. (2012). Influence of chewing gum packaging design on consumer expectation and willingness to buy. An analysis of functional, sensory and experience attributes. Food Quality and Preference, 24(1), 162-170. https://doi.org/10.1016/j.foodqual.2011.10.011

[9] Chimboza, D. \& Mutandwa, E. (2007). Measuring the determinants of brand preference in a dairy product market. African Journal of Business Management, 1(9), 230-237.

[10] Zeithaml, V. A. (1988). Consumer perceptions of price, quality, and value: a means-end model and synthesis of evidence. Journal of Marketing, 52(3), 2-22. https://doi.org/10.1177/002224298805200302

[11] Grunert, K. G., Beck-Larson, T., \& Bredahl, L. (2000). Three issues in consumer quality perception and acceptance of dairy products. International Dairy Journal, 10(8), 575-584. https://doi.org/10.1016/S0958-6946(00)00085-6

[12] Gagula, G., Mastanjević, K., Mastanjević, K., Krstanović, V., Horvat, D., \& Magdić, D. (2020). The influence of packaging material on volatile compounds of pale lager beer. Food Packaging and Shelf Life, 24, 100496 https://doi.org/10.1016/j.fpsl.2020.100496

[13] Silayoi, P. \& Speece, M. (2007). The importance of packaging attributes: a conjoint analysis approach. European Journal of Marketing, 41(11/12), 1495-1517.

\section{https://doi.org/10.1108/03090560710821279}

[14] Marsh, K. \& Bugusu, B. (2007). Food Packaging - Roles, Materials and Environmental Issues. Journal of Food Science, 72(3), 39-55. https://doi.org/10.1111/j.1750-3841.2007.00301.x

[15] Hudika, T., Tomašegović, T., Cigula, T., \& Prša, M. (2020). Polycaprolactone primers with zinc oxide and silicon dioxidenanoparticles for paper substrates: Influence on the properties of cyan and magenta offset prints. Coloration Technology, 136, 435-449. https://doi.org/10.1111/cote.12487

[16] Triantafyllou, V. I., Akrida-Demertzi, K., \& Demertzis, P. G. (2007). A study on the migration of organic pollutants from recycled paperboard packaging materials to solid food matrices. Food Chemistry, 101(4), 1759-1768. https://doi.org/10.1016/j.foodchem.2006.02.023

[17] Majeed, K., Jawaid, M., Hassan, A., Abu Bakar, A., Abdul Khalil, H. P. S., Salema, A. A., \& Inuwa, I. (2013). Potential materials for food packaging from nanoclay/natural fibres filled hybrid composites. Material \& Design, 46, 391-410. https://doi.org/10.1016/.matdes.2012.10.044

[18] Mensitieri, G., Di Maio, E., Buonocore, G. G., Nedi, I., Oliviero, M., Sansone, L., \& Iannace, S. (2011). Processing and shelf life issues of selected food packaging materials and structures from renewable resources. Trends in Food Science \& Technology, 22(2-3), 72-80. https://doi.org/10.1016/j.tifs.2010.10.001

[19] Tang, X. Z., Kumar, P., Alavi, S., \& Sandeep, K. P. (2012). Recent Advances in Biopolymers and Biopolymer-Based Nanocomposites for Food Packaging Materials. Critical Reviews in Food Science and Nutrition, 52(5), 426-442. https://doi.org/10.1080/10408398.2010.500508

[20] Llorens, A., Lloret, E., Picouet, P. A., Trbojevich, R., \& Fernandez, A. (2012). Metallic-based micro and nanocomposites in food contact materials and active food packaging. Trends in Food Science \& Technology, 24(1), 1929. https://doi.org/10.1016/j.tifs.2011.10.001

[21] Lindh, H., Olsson, A., \& Williams, H. (2016). Consumer Perceptions of Food Packaging: Contributing to or Counteracting Environmentally Sustainable Development? Packaging Technology and Science, 29(1), 3-23. https://doi.org/10.1002/pts.2184

[22] Williams, H., Wikström, F., \& Löfgren, M. (2008). A life cycle perspective on environmental effects of customer focused packaging development. Journal of Cleaner Production, 16(7), 853-859. https://doi.org/10.1016/j.jclepro.2007.05.006

[23] Duizer, L. M., Robertson, T., \& Han, J. (2009). Requirements for packaging from an ageing consumer's perspective. Packaging Technology and Science, 22(4), 187197. https://doi.org/10.1002/pts.834

[24] Eldesouky, A., Pulido, A. F., \& Mesias, F. J. (2015). The Role of Packaging and Presentation Format in Consumers' Preferences for Food: An Application of Projective Techniques. Journal of sensory studies, 30(5), 360-369. https://doi.org/10.1111/joss.12162

[25] Kim, M. K. \& Lee, K. G. (2015). Influences of intrinsic and extrinsic factors on consumer acceptance of orange juice using consumer liking testing and Kano analysis techniques. Food Science and Biotechnology, 24(5), 1687-1693. https://doi.org/10.1007/s10068-015-0219-4

[26] Drašković, N., Temperley, J., \& Pavičić, J. (2009). Comparative Perception(s) of Consumer Goods Packaging: Croatian Consumers' Perspective. International journal of management cases, 11(2), 154-163.

[27] Kano, N., Seraku, N., Takahashi, F., \& Tsjui, S. (1984). Attractive Quality and Must-Be Quality, Journal of the Japanese Society for Quality Control, 41, 39-48.

[28] Löfgren, M. \& Nilsson, L. (2005). Kano's Theory of Attractive Quality and Packaging. Quality Management Journal, 12(3), 7-20. 
https://doi.org/10.1080/10686967.2005.11919257

[29] Wikström, L. (2002). Produktensbudskap: metoderförvärderingavprodukterssemantiskafunktioneruret tanvändarperspektiv. Unpublished $\mathrm{PhD}$ thesis, Chalmers University of Technology, Gothenburg, Sweden

[30] Vukoje, M., Kulčar, R., Itrić, K., \& Rožić, M. (2018). Spectroscopic evaluation of thermochromic printed cardboard biodegradation. Proceedings - The Ninth International Symposium GRID 2018, 87-96. https://doi.org/10.24867/GRID-2018-p10

[31] Berger, C., Blauth, R., Boger, D., Bolster, C., Burchill, G., DuMouchel, W., Pouliot, F., Richter, R., Rubinoff, A., Shen, D., Timko, M., \& Walden, D. (1993). Kano's methods for understanding customer-defined quality. Quality Management Journal, 2(4), 2-36

[32] Magnier, L., Schoormans, J., \& Mugge, R. (2016). Judging a product by its cover: Packaging sustainability and perceptions of quality in food products. Food Quality and Preference, 53, 132-142. https://doi.org/10.1016/j.foodqual.2016.06.006

[33] Vilnai-Yavetz, I. \& Koren, R. (2013) Cutting through the clutter: purchase intentions as a function of packaging instrumentality, aesthetics, and symbolism. The International Review of Retail Distribution and Consumer Research, 23(4), 394-417. https://doi.org/10.1080/09593969.2013.792743

[34] Hurley, R. A., Galvarino, J., Thackston, E., Ouzts, A., \& Pham, A. (2013). The effect of modifying structure to display product versus graphical representation on packaging. Packaging Technology and Science, 26(8), 453460. https://doi.org/10.1002/pts.1996

[35] Sabo, B., Bečica, T., Keleš, N., Kovačević, D., \& Brozović, M. (2017). The impact of packaging transparency on product attractiveness, Journal of Graphic Engineering and Design, 8(2), 5-9. https://doi.org/10.24867/JGED-2017-2-005

[36] Sharif Ullah, A. M. M. \& Tamaki, J. (2011). Analysis of Kano-model-based customer needs for product development. Systems Engineering, 14(2), 154-172. https://doi.org/10.1002/sys.20168

[37] Klaiman, K., Ortega, D. L., \& Garnache, C. (2016). Consumer preferences and demand for packaging material and recyclability. Resources, Conservation and Recycling, 115, 1-8. https://doi.org/10.1016/j.resconrec.2016.08.021

[38] Susilo, B., Lestari, M. W. H., \& Rohim, A. (2020). Impact of using low-cost packaging material of commercial herbal oil on its antibacterial compounds. All Life, 13(1), 516-523. https://doi.org/10.1080/26895293.2020.1817800

[39] Arboretti, R. \& Bordignon, P. (2016). Consumer preference in food packaging: cub models and conjoint analysis. British Food Journal, 118(3), 527-540. https://doi.org/10.1108/BFJ-04-2015-0146

[40] Löfgren, M., Witell, L., \& Gustafsson, A. (2011). Theory of attractive quality and life cycles of quality attributes. The TQM Journal, 23(2), 235-246. https://doi.org/10.1108/17542731111110267

\section{Contact information:}

Maja BROZOVIć, PhD, Full Professor

(Corresponding author)

Faculty of Graphic Arts, University of Zagreb,

Getaldićeva 2, 10000 Zagreb, Croatia

E-mail: maja.brozovic@grf.unizg.hr

Dorotea KOVAČEVIĆ, PhD, Postdoctoral Researcher,

(Corresponding author)

Faculty of Graphic Arts, University of Zagreb,

Getaldićeva 2, 10000 Zagreb, Croatia

E-mail: dorotea.kovacevic@grf.unizg.hr

Josip BOTA, PhD, Postdoctoral Researcher Faculty of Graphic Arts, University of Zagreb, Getaldićeva 2, 10000 Zagreb, Croatia

E-mail: Josip.bota@grf.unizg.hr 